\title{
Properties Design: Prediction and Experimental Validation of the Luminescence Properties of a New Eu(II)-based Phosphor
}

\author{
A. García-Fuente, F. Baur, F. Cimpoesu, A. Vega, T. Jüstel, W. Urland ${ }^{[a]}$
}

\begin{abstract}
We present here our theoretical model that allows to predict, for the first time, the luminescence properties of a new phosphor $\left(\mathrm{BaSnSi}_{3} \mathrm{O}_{9}: \mathrm{Eu}^{2+}\right)$ before the experiment is performed. The predicted emission wavelength, $488 \mathrm{~nm}$ with a $64 \mathrm{~nm}$ bandwidth, is confirmed by subsequent experimental work. The method consists in a multielectronic Hamiltonian parametrized from ab initio calculations. The luminescence properties of other similar compounds $\left(\mathrm{BaHfSi}_{3} \mathrm{O}_{9}: \mathrm{Eu}^{2+}\right.$ and $\left.\mathrm{BaZrSi}_{3} \mathrm{O}_{9}: \mathrm{Eu}^{2+}\right)$, for which there is already experimental information, are also correctly reproduced.
\end{abstract}

The development of new phosphors with novel luminescence properties is a distinct challenge of applied research. ${ }^{1-5} \mathrm{New}$ phosphors are essential for the design of new lighting devices, but they have also become relevant in other fields such as medicine,${ }^{6,7}$ horticulture,${ }^{7,8}$ photovoltaics ${ }^{9}$ or quantum information technology. ${ }^{10}$ Certain lanthanide ions, as is the case of $\mathrm{Eu}^{2+}$, are well suited by the placement in visible spectra of emissions due to electric-dipole allowed $[\mathrm{Xe}] 4 \mathrm{f}^{\mathrm{n}} \leftrightarrow[\mathrm{Xe}] 4 \mathrm{f}^{\mathrm{n}-1} 5 \mathrm{~d}^{1}$ transitions. The particular host plays a key role in the fine tuning of absorption vs emission energies.

The theoretical calculation of the luminescence properties of lanthanide ions has also attracted a lot of attention, both with semi-empirical ${ }^{11,12}$ and $a b$ initio methods. ${ }^{13-22}$ However, all these works focus on reproducing and understanding the available experimental data. We present here the first-ever theoretical prediction of a brand-new phosphor based on ab initio calculations, that is also confirmed by experimental data afterwards. The developed model will thus also allow to understand quantitatively unusual luminescent behavior, like a significant red shift, in host compounds doped with $\mathrm{Eu}^{3+}$ which has been interpreted only qualitatively. ${ }^{23}$

\section{[a] A. García-Fuente}

Departamento de Física

Universidad de Oviedo, E-22007 Oviedo, Spain.

F. Baur

Department of Chemical Engineering

Münster University of Applied Sciences, D-48565 Steinfurt, Germany.

F. Cimpoesu

Institute of Physical Chemistry, 060021 Bucharest, Romania.

A. Vega

Departamento de Física Teórica, Atómica y Óptica

Universidad de Valladolid, E-47011 Valladolid, Spain.

T. Jüstel

Department of Chemical Engineering

Münster University of Applied Sciences, D-48565 Steinfurt, Germany. W. Urland

Private Institute of Theoretical Chemical Physics, $\mathrm{CH}-6600$ Muralto,

Switzerland

Supporting Information for this article is given via a link at the end of the document.
In particular, we focus on $\mathrm{Eu}^{2+}$ doped host compounds $\mathrm{BaMSi}_{3} \mathrm{O}_{9}(\mathrm{M}=\mathrm{Hf}, \mathrm{Zr}, \mathrm{Sn})$. The given structure type is depicted in Figure 1. It presents one $\mathrm{Ba}^{2+}$ site that can be used for $\mathrm{Eu}^{2+}$ doping. In that case $\mathrm{Eu}^{2+}$ is surrounded by six $\mathrm{SiO}_{4}{ }^{4-}$ groups, with the closest six oxygen atoms at the same distance, forming a face-compressed octahedron with $D_{3}$ local symmetry. The phosphor $\mathrm{BaHfSi}_{3} \mathrm{O}_{9}: \mathrm{Eu}^{2+}$ has already been experimentally synthesized and tested, showing an intense blue-green emission centered at $475 \mathrm{~nm} .{ }^{24}$ The $\mathrm{BaZrSi}_{3} \mathrm{O}_{9}: \mathrm{Eu}^{2+}$ material has the emission peak between $475 \mathrm{~nm}^{25}$ and $479 \mathrm{~nm},{ }^{26}$ according to different syntheses. This work started from the idea of predicting a new phosphor completely from first principles using ab initio calculations and well-tempered phenomenological Hamiltonians, verifying a posteriori the a priori predictions. Thus, we proposed the $\mathrm{BaSnSi}_{3} \mathrm{O}_{9}: \mathrm{Eu}^{2+}$ system, for which there was no preliminary experimental data. The deal is corroborated with the reproduction of the available experimental data for $\mathrm{BaHfSi}_{3} \mathrm{O}_{9}: \mathrm{Eu}^{2+}$ and $\mathrm{BaZrSi}_{3} \mathrm{O}_{9}: \mathrm{Eu}^{2+}$.
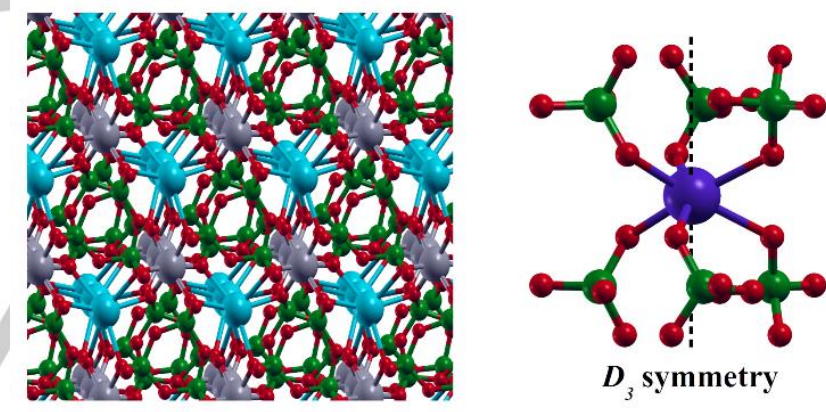

Figure 1. Representation of the $\mathrm{BaMSi}_{3} \mathrm{O}_{9}(\mathrm{M}=\mathrm{Hf}, \mathrm{Zr}, \mathrm{Sn})$ structure (left) and of the local structure around the $\mathrm{Eu}^{2+}$ activator (right) showing local $D_{3}$ symmetry. Light blue, red, green, grey and purple spheres are used to represent $\mathrm{Ba}, \mathrm{O}, \mathrm{Si}, \mathrm{M}$ and $\mathrm{Eu}$ atoms, respectively.

The modelling is a two-step process. The first step consists in the structural optimization, by density functional theory (DFT) calculations, of a periodic supercell of $\mathrm{BaMSi}_{3} \mathrm{O}_{9}(\mathrm{M}=\mathrm{Hf}, \mathrm{Zr}, \mathrm{Sn})$ doped with $\mathrm{Eu}^{2+}$ in a $\mathrm{Ba}^{2+}$ site. A non-routine essential aspect is the DFT emulation of both the ground electronic configuration $4 \mathrm{f}^{7}$ (GC) and the excited electronic configuration $4 f^{6} 5 \mathrm{~d}(\mathrm{EC})$ of $\mathrm{Eu}^{2+}$ Table 1 shows the Eu-O coordination bond lengths in the different structures, as function of the established configuration. Note that the EC structures always present shorter bond distances than the GC structures, what seems apparently counterintuitive. However, this phenomena has already been reported both theoretically ${ }^{15,27}$ and experimentally ${ }^{28,29}$ for other lanthanide doped phosphors. The fact is that because, while the f-shell does not contribute to chemical bonding, the formally $5 d$ virtuals are responsible for the stabilization of $f$-type complexes. Consequently, the $f^{6} d$ EC states are more bonded, with shorter Eu-O contacts. 
Table 1. Relaxed distances between the $\mathrm{Eu}^{2+}$ activator and its closest oxygen atoms in the different $\mathrm{BaMSi}_{3} \mathrm{O}_{9}: \mathrm{Eu}^{2+}$ structures.

\begin{tabular}{ccc}
\hline System & Eu-O (GC) & Eu-O (EC) \\
\hline $\mathrm{BaHfSi}_{3} \mathrm{O}_{9}: \mathrm{Eu}^{2+}$ & $2.556 \AA$ & $2.515 \AA$ \\
$\mathrm{BaZrSi}_{3} \mathrm{O}_{9}: \mathrm{Eu}^{2+}$ & $2.547 \AA$ & $2.498 \AA$ \\
$\mathrm{BaSnSi}_{3} \mathrm{O}_{9}: \mathrm{Eu}^{2+}$ & $2.548 \AA$ & $2.449 \AA$ \\
\hline
\end{tabular}

In a second step, we use the DFT results to parametrize a multielectronic Hamiltonian operator that describes the valence states of the $\mathrm{Eu}^{2+}$ ion embedded in the host. Our Hamiltonian can be decomposed as:

$$
H=H_{0}+H_{C F}+H_{E E}+H_{S O}
$$

where $H_{0}$ and $H_{C F}$ are one-electron terms, originating from intraatomic and crystal field, respectively, while $H_{E E}$ and $H_{S O}$ stand for electron-electron and spin-orbit interactions. We considered an extended configuration interaction $(\mathrm{Cl})$ constructed with Slater Determinants (SDs) made of pseudo-atomic wavefunctions of $f$ and $d$ types. The basis is built merging the full $\mathrm{Cl}$ within the $4 \mathrm{f}^{7}$ and $4 \mathrm{f}^{6} 5 \mathrm{~d}$ configurations, amounting 3432 SDs and $30030 \mathrm{SDs}$, respectively. Although some luminescence properties of $\mathrm{Eu}^{2+}$-based phosphors can be obtained from simplified approaches, ${ }^{17,30}$ here we deal with the complete diagonalization of the $H$ matrix of dimension 33462, a computational challenge that only modern computers are able to achieve.

As customary in Crystal Field (CF) Theory the inter-electron part is parameterized with the so-called Slater-Condon integrals. ${ }^{31,32}$ For the inter-shell effect, the $F_{k}(4 \mathrm{f}, 5 \mathrm{~d}$ ) elements (with $k=0,2,4)$ are accounting for Coulomb interaction, while the $G_{k}(4 \mathrm{f}, 5 \mathrm{~d})$ (with $k=1,3,5)$ are yielding the exchange part. Within the $4 f$ shell, both effects are termed with the $F_{k}(4 \mathrm{f}, 4 \mathrm{f})$ integrals (with $k=2,4$, 6 ). We calculate $F_{k}$ and $G_{k}$ by numerical integration of the radial $4 \mathrm{f}$ and $5 \mathrm{~d}$ wavefunctions of the free $\mathrm{Eu}^{2+}$ ion as obtained from DFT calculations, with a correction introduced to reproduce the available experimental data. ${ }^{19}$ The results are shown in the second column of Table 2 .

$H_{S O}$ can be written in terms of a spin-orbit coupling parameter $\xi(n l)$ for each electronic shell, obtained from the orbital splitting from DFT calculations including spin-orbit interaction ${ }^{19}$ (see Table 2).

Due to the delocalization of the $5 \mathrm{~d}$ states when the $\mathrm{Eu}^{2+}$ ion is embedded in the $\mathrm{BaMSi}_{3} \mathrm{O}_{9}$ host lattice, the $F_{k}(4 \mathrm{f}, 5 \mathrm{~d}), G_{k}(4 \mathrm{f}, 5 \mathrm{~d})$ and $\xi(5 \mathrm{~d})$ are reduced respect to their values for the free ion (that is, the nephelauxetic effect). We calculate a reduction factor to these parameters $\beta$ from the amount of delocalization of the $5 \mathrm{~d}$ states over the surrounding $\mathrm{O}^{2-}$ ions in the host. We find $\beta=0.91$ for all our systems. In turn, the f-only parameters of the embedded ion are practically the same of the free one. Results are given in the third column of Table 2 . The $\Delta(\mathrm{fd})$ parameter cumulates $H_{0}$ and $H_{E E}$ terms forming the traces of the Hamiltonain blocks based on $4 f^{7}$ versus $4 f^{6} 5 d$ manifolds. Since $\Delta(\mathrm{fd})$ is not influenced by $C F$ effects, it will be fixed to the same value for all the different $\mathrm{BaMSi}_{3} \mathrm{O}_{9}: \mathrm{Eu}^{2+}$ compounds, based on the value fit from the $475 \mathrm{~nm}$ experimental emission wavelength in the $\mathrm{BaHfSi}_{3} \mathrm{O}_{9}: \mathrm{Eu}^{2+}$ case. ${ }^{24}$

Table 2. Slater-Condon parameters of the free $\mathrm{Eu}^{2+}$ ion (second column) and of the $\mathrm{Eu}^{2+}$ embedded in the $\mathrm{BaMSi}_{3} \mathrm{O}_{9}$ host lattice.

\begin{tabular}{ccc}
\hline Parameter & ${\text { free } \mathrm{Eu}^{2+} \text { ion }\left(\mathrm{cm}^{-1}\right)}$ & $\mathrm{BaMSi}_{3} \mathrm{O}_{9}: \mathrm{Eu}^{2+}\left(\mathrm{cm}^{-1}\right)$ \\
\hline$F_{2}(4 \mathrm{f}, 4 \mathrm{f})$ & 385.1 & 385.1 \\
$F_{4}(4 \mathrm{f}, 4 \mathrm{f})$ & 49.8 & 49.8 \\
$F_{6}(4 \mathrm{f}, 4 \mathrm{f})$ & 5.3 & 5.3 \\
$G_{1}(4 \mathrm{f}, 5 \mathrm{~d})$ & 256.2 & 233.2 \\
$F_{2}(4 \mathrm{f}, 5 \mathrm{~d})$ & 170.4 & 155.0 \\
$G_{3}(4 \mathrm{f}, 5 \mathrm{~d})$ & 22.5 & 20.5 \\
$F_{4}(4 \mathrm{f}, 5 \mathrm{~d})$ & 12.8 & 11.7 \\
$G_{5}(4 \mathrm{f}, 5 \mathrm{~d})$ & 3.5 & 3.2 \\
$\xi(4 \mathrm{f})$ & 1363 & 1363 \\
$\xi(5 \mathrm{~d})$ & 806 & 733 \\
$\Delta(\mathrm{fd})$ & 5576 & -3345 \\
\hline & &
\end{tabular}

The essential $H_{L F}$ part in the multielectronic Hamiltonian was tackled taking directly from the $\Gamma$ point of the DFT band calculations the $7 \times 7$ and $5 \times 5$ orbital blocks corresponding to the one-electron $V_{L F}$ potential acting on the $4 f$ and $5 d$ states, respectively.

We show in the left panel of Figure 2 the energy splitting of the $5 \mathrm{~d}$ states of $\mathrm{Eu}^{2+}$ inside $\mathrm{BaSnSi}_{3} \mathrm{O}_{9}$ and for the $\mathrm{GC}$ and EC structures. A complete list of CF parameters is shown in Table $\mathrm{S} 1$ of the Supporting Information (SI). With all these components, we diagonalize $H$ and calculate the energy levels and eigenfunctions. From that, we can calculate the dipolar transition probabilities (DTP) between states with the dipole operator. The right panel of Figure 2 shows the energy levels of the different $4 f^{7}$ and $4 f^{6} 5 d$ manifolds. Similar results are found for $\mathrm{BaHfSi}_{3} \mathrm{O}_{9}: \mathrm{Eu}^{2+}$ and $\mathrm{BaZrSi}_{3} \mathrm{O}_{9}: \mathrm{Eu}^{2+}$, a comparison between the three cases is shown in Figure $\mathrm{S} 1$ (SI). For each structure, the lowest $4 f^{6} 5 d$ state is lower in energy in the EC than in the GC, in agreement with the larger crystal field splitting, also shown in Figure 2, corresponding to the shorter bond lengths (Table 1).
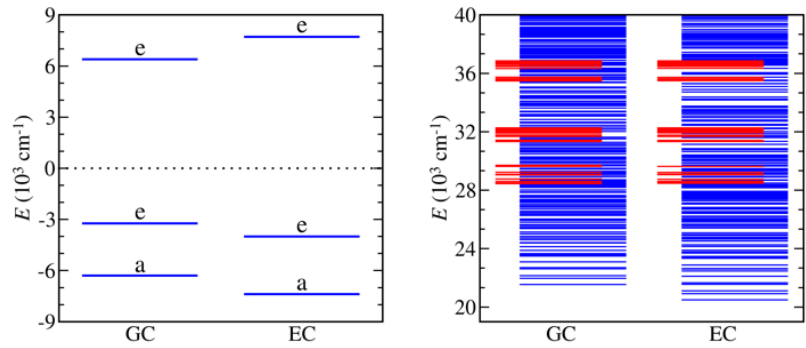

Figure 2. Calculated crystal field energy levels of the $5 \mathrm{~d}$ states, relative to their barycenter (left) and multielectronic energy states (right) of $\mathrm{BaSnSi}_{3} \mathrm{O}_{9}: \mathrm{Eu}^{2+}$ in the GC and EC structures. The crystal field levels also indicate their parentage: blue and red lines are used for the $4 f^{7}$ and $4 f^{6} 5 d$ manifolds, respectively. The zero of the scale corresponds to the lowest state. 
The emission wavelength from $\mathrm{Eu}^{2+}$ corresponds to the energy difference between the lowest $4 f^{6} 5 d$ state and the $4 f^{7}$ ground state in the $\mathrm{EC}$ structure. We calculate an emission wavelength of $475 \mathrm{~nm}$ for both $\mathrm{BaHfSi}_{3} \mathrm{O}_{9}: \mathrm{Eu}^{2+}$ and $\mathrm{BaZrSi}_{3} \mathrm{O}_{9}: \mathrm{Eu}^{2+}$, in agreement with the experimental data. ${ }^{24,25}$ For $\mathrm{BaSnSi}_{3} \mathrm{O}_{9}: \mathrm{Eu}^{2+}$ we predict an emission wavelength of $488 \mathrm{~nm}$.

A relevant parameter for the use of a phosphor in a particular application is the width of the emission peak. In order to estimate this width, we estimate the Franck-Condon (FC) factors, ${ }^{33}$ that indicate the coupling between different vibrational modes of the GC and EC configurations. We simplify the problem by just considering one vibrational mode. A complete description of the calculation of the FC factors is given in the SI. The computed FC factors are depicted as vertical blue lines in Figure 3. The emission spectra can be simulated as the envelope of the discrete spectrum made of $F_{n}$ values, obtaining a full width at half maximum (FWHM) of $48 \mathrm{~nm}$ for $\mathrm{BaHfSi}_{3} \mathrm{O}_{9}: \mathrm{Eu}^{2+}$, in good agreement with the experimental data that finds FWHM 50 nm. ${ }^{24}$ For $\mathrm{BaZrSi}_{3} \mathrm{O}_{9}: \mathrm{Eu}^{2+}$ we obtain a FWHM of $43 \mathrm{~nm}$, somewhat below the experimental data of FWHM 55 nm. ${ }^{25}$ Finally, we predict a FWHM of $64 \mathrm{~nm}$ for $\mathrm{BaSnSi}_{3} \mathrm{O}_{9}: \mathrm{Eu}^{2+}$.

To verify our predictions, we have synthesized pure and $\mathrm{Eu}^{2+}(5$ mol-\%) doped $\mathrm{BaSnSi}_{3} \mathrm{O}_{9}$. X-ray diffraction (XRD) results are given in Figure $\mathrm{S} 2(\mathrm{SI})$. It is known that $\mathrm{BaTiSi}_{3} \mathrm{O}_{9}$ shows blue luminescence upon UV excitation, that has been assigned to a charge transfer (CT) transition within the $\mathrm{TiO}_{6}$ octahedra. ${ }^{34}$ This blue luminescence was also observed in natural $\mathrm{Ba}(\mathrm{Sn}, \mathrm{Ti}) \mathrm{Si}_{3} \mathrm{O}_{9}{ }^{35}$ and synthetic lattices like $\mathrm{BaSnSi}_{3} \mathrm{O}_{9}: \mathrm{Ti}^{4+}$ and $\mathrm{BaZrSi}_{3} \mathrm{O}_{9}: \mathrm{Ti}^{4+}{ }^{36}$ Synthetic, Ti-free $\mathrm{BaZrSi}_{3} \mathrm{O}_{9}$ luminesces with a maximum at $290 \mathrm{~nm}$ that was assigned to a CT process within the $\mathrm{ZrO}_{6}$ octahedra. ${ }^{37}$ It is conceivable that $\mathrm{BaSnSi}_{3} \mathrm{O}_{9}$ will show $\mathrm{SnO}_{6} \mathrm{CT}$ luminescence, however, at room temperature no luminescence was observed by Fujiwara et al. ${ }^{36}$ Our measurements on an undoped $\mathrm{BaSnSi}_{3} \mathrm{O}_{9}$ samples confirm this finding. CT luminescence often exhibits low quenching temperatures and it might be completely vanishing at $300 \mathrm{~K}$.

Figure 4 shows excitation and emission spectra of $\left(\mathrm{Ba}_{0.95} \mathrm{Eu}_{0.05}\right) \mathrm{SnSi}_{3} \mathrm{O}_{9}$ recorded at $4 \mathrm{~K}$ and at room temperature, respectively. The excitation spectrum (green lines) shows a strong temperature dependence. At $4 \mathrm{~K}$ (dark green line) the band is considerably broader and shows structuring. The structure is caused by the various possible $4 f^{6} 5 d^{1}$ energy levels with non-vanishing DTP from the ground state, as shown in Figure 3. At room temperature (light green line) broadening of the individual lines results in the appearance of an unstructured band. The excitation is also considerably narrower at room temperature as the high energy part vanishes. The reflection spectrum of the undoped sample (Figure 5, black line) indicates that the conduction band begins at $350 \mathrm{~nm}$ and overlaps the $5 \mathrm{~d}$ states of $\mathrm{Eu}^{2+}$. At room temperature this overlap hinders efficient excitation of $\mathrm{Eu}^{2+}$ at these wavelengths. At $4 \mathrm{~K}$ less mixing of the $5 \mathrm{~d}$ states and the conduction band occurs and $\mathrm{Eu}^{2+}$ can be excited in this spectral region. Additionally, at room temperature an incision in the excitation spectrum is found at $395 \mathrm{~nm}$ due to a competing ${ }^{7} \mathrm{~F}_{0} \rightarrow{ }^{5} \mathrm{~L}_{6}$ absorption from $\mathrm{Eu}^{3+}$ impurities.
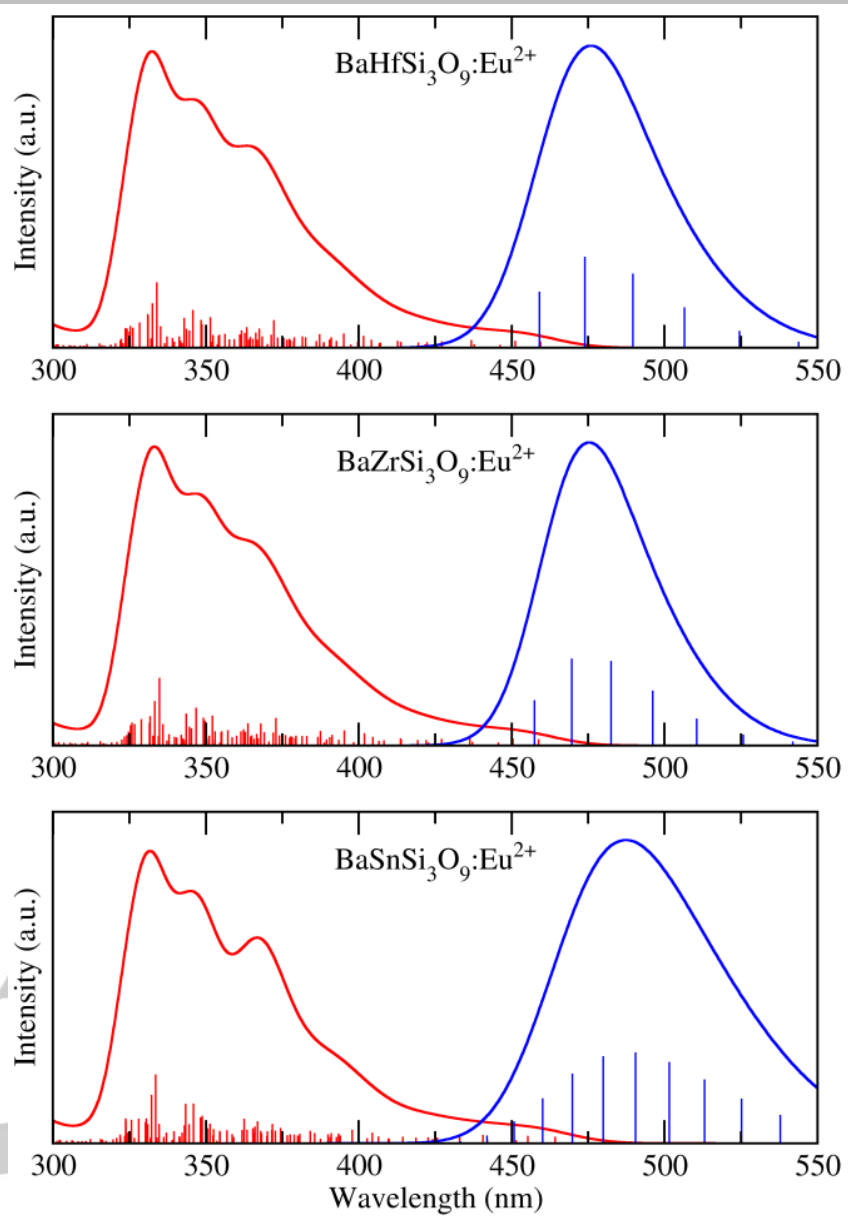

Figure 3. Calculated absorption (red curves) and emission (blue curves) spectra of $\mathrm{BaMSi}_{3} \mathrm{O}_{9}: \mathrm{Eu}^{2+}$. Vertical red lines indicate the DTP from the $4 \mathrm{f}^{7}$ ground state to the $4 f^{6} 5 \mathrm{~d}$ manifold. Vertical blue lines indicate Franck-Condon factors from the lowest vibrational mode of the lowest $4 f^{6} 5 d$ state to the different vibrational modes of the $4 f^{7}$ ground state.

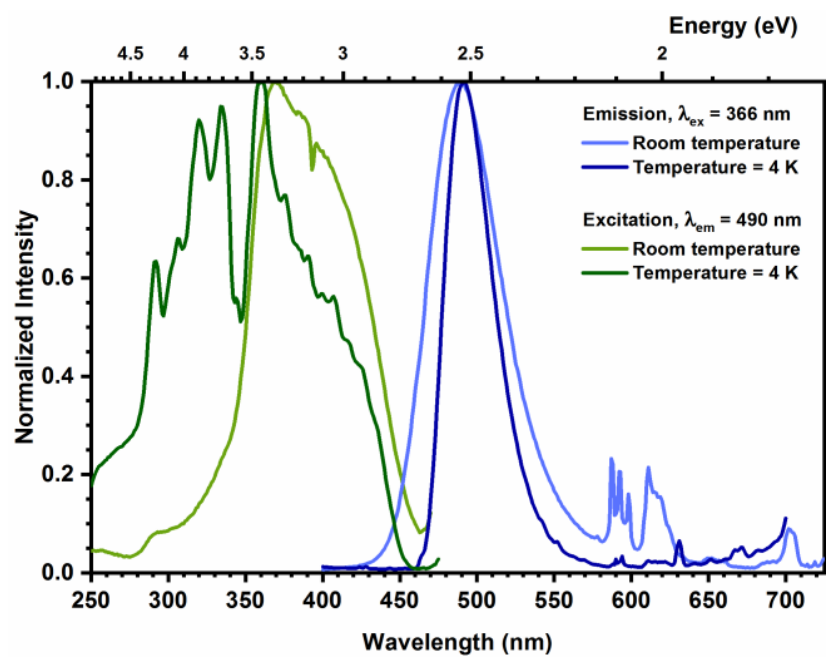

Figure 4. Experimental excitation spectra (green lines) monitoring the $490 \mathrm{~nm}$ emission peak at $4 \mathrm{~K}$ (dark green line) and at room temperature (light green line) and emission spectra (blue lines) upon $366 \mathrm{~nm}$ excitation at $4 \mathrm{~K}$ (dark blue line) and at room temperature (light blue line) of $\left(\mathrm{Ba}_{0.95} \mathrm{Eu}_{0.05}\right) \mathrm{SnSi}_{3} \mathrm{O}_{9}$. 
Upon excitation at $366 \mathrm{~nm}$, an emission band (blue lines) with a maximum at $490 \mathrm{~nm}$ can be observed, which is very close to the predicted value of $488 \mathrm{~nm}$. The emission spectrum is narrower at $4 \mathrm{~K}$ (dark blue line) than at room temperature (light blue line). This behavior is commonly observed and is a result of decreased coupling with vibrational states. The FWHM at $4 \mathrm{~K}$ is quite smaller than our prediction, indicating that our simplified model with just one vibrational mode might be an oversimplification. Fortunately, just like for $\mathrm{BaHfSi}_{3} \mathrm{O}_{9}: \mathrm{Eu}^{2+}$ and $\mathrm{BaZrSi}_{3} \mathrm{O}_{9}: \mathrm{Eu}^{2+}$, our prediction fits well with the emission spectra at room temperature. Furthermore, at room temperature emission lines of $\mathrm{Eu}^{3+}$ are found between 580 and $710 \mathrm{~nm}$, originating from the ${ }^{5} \mathrm{D}_{0}$ to ${ }^{7} \mathrm{~F}_{0-4}$ transitions. At $4 \mathrm{~K}$ the relative intensity of the $\mathrm{Eu}^{2+}$ emission is much stronger and the $\mathrm{Eu}^{3+}$ lines cannot be as easily discerned. The reason for this is the low thermal quenching temperature of the $\mathrm{Eu}^{2+}$ emission as discussed later in this publication. The $\mathrm{Eu}^{3+}$ impurities can be diminished by use of a reducing atmosphere during annealing. However, this caused a brownish body color and strong decrease in luminescence intensity. This is caused by the reduction of $\mathrm{Sn}^{4+}$ and consequently by the formation of oxygen vacancies.

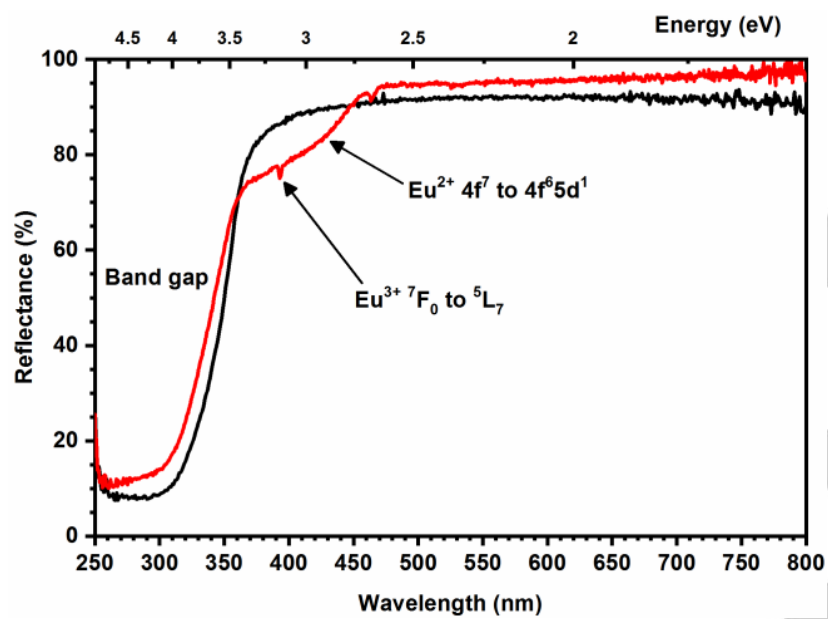

Figure 5. Reflectance spectrum of $\left(\mathrm{Ba}_{0.95} \mathrm{Eu}_{0.05}\right) \mathrm{SnSi}_{3} \mathrm{O}_{9}$ (red line) and $\mathrm{BaSnSi}_{3} \mathrm{O}_{9}$ (black line).

The photoluminescence quantum yield upon $366 \mathrm{~nm}$ excitation has been determined and found to be $17 \% \pm 5 \%$. To investigate the reason for this low quantum efficiency, emission spectra were recorded at temperatures from 77 to $500 \mathrm{~K}$. The emission intensity was integrated in the range of 430 to $675 \mathrm{~nm}$, the integrals being plotted over temperature (see Figure 6(a)). The experimental data were fitted to the Mott formula, to obtain the activation energy for the quenching process, finding a $E_{a}=(0.39$ $\pm 0.02) \mathrm{eV}$ value. This energy corresponds to a thermal quenching temperature $\mathrm{T}_{1 / 2}$ of $267 \mathrm{~K}$. For $\mathrm{BaZrSi}_{3} \mathrm{O}_{9}: \mathrm{Eu}^{2+} \mathrm{a}$ higher $T_{1 / 2}$ of approximately $450 \mathrm{~K}$ was reported. ${ }^{22}$ This difference can be explained if thermal quenching in these materials is caused by photo-ionization. This is a quenching mechanism where a localized electron in an excited state is further excited to the conduction band and consequently delocalized. If the energy difference between the excited state and the bottom of the conduction band is small enough, thermal energy can suffice to ionize the $\mathrm{Eu}^{2+}$ ion. Therefore, this quenching mechanism usually plays a role in phosphors with a small band gap and high excitation energies, such as
$\mathrm{LaAlO}_{3}: \mathrm{Ce}^{3+38-40}$ The larger band gap of $\mathrm{BaZrSi}_{3} \mathrm{O}_{9}$ in comparison to $\mathrm{BaSnSi}_{3} \mathrm{O}_{9}$ apparently results in a larger distance between the bottom of the conduction band and the excited state of $\mathrm{Eu}^{2+}$ and thus in a higher thermal quenching temperature.
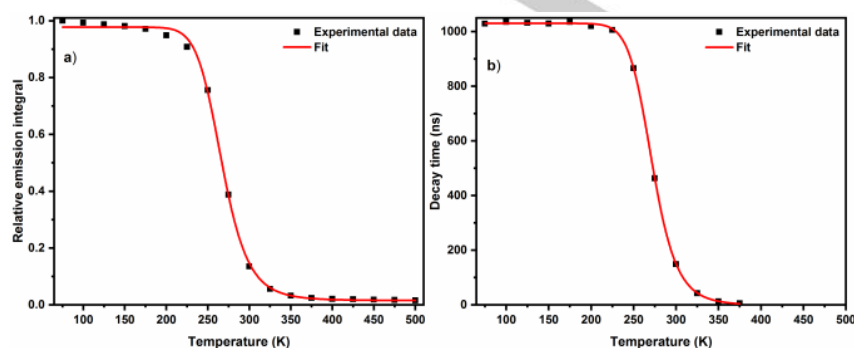

Figure 6. (a) Emission integral of $\left(\mathrm{Ba}_{0.95} \mathrm{Eu}_{0.05}\right) \mathrm{SnSi}_{3} \mathrm{O}_{9}$ upon $366 \mathrm{~nm}$ excitation in dependence on the temperature. (b) Decay times of the $490 \mathrm{~nm}$ emission of $\left(\mathrm{Ba}_{0.95} \mathrm{Eu}_{0.05}\right) \mathrm{SnSi}_{3} \mathrm{O}_{9}$ upon $375 \mathrm{~nm}{ }^{\text {excitation }}$ at temperatures from 77 to $375 \mathrm{~K}$.

To verify that the observed emission of $\left(\mathrm{Ba}_{0.95} \mathrm{Eu}_{0.95}\right) \mathrm{SnSi}_{3} \mathrm{O}_{9}$ consists in $\mathrm{Eu}^{2+}$ luminescence, the decay curves of the $490 \mathrm{~nm}$ emission, upon $375 \mathrm{~nm}$ excitation, were recorded at temperatures from 77 to $375 \mathrm{~K}$ (see Figure S3 of SI). The decay is mono-exponential, the half -time decreasing strongly with increasing temperature. A mono-exponential decay curve indicates a rather low defect density and a very homogeneous distribution of defects and activator ions in the crystallites. ${ }^{41-45}$ The decay curves were fitted to obtain the decay times, which are plotted in Figure 6(b). The sigmoidal trend of the decay parameters is typical for thermal quenching of the luminescence. By fitting the decay as function of temperature, the activation energy is obtained: $E_{a}=0.44 \mathrm{eV} \pm 0.01 \mathrm{eV}$, corresponding to a thermal quenching temperature $T_{1 / 2}$ of $272 \mathrm{~K}$. This value is in very good agreement with that derived from the emission intensity. It can be concluded that the emission certainly arises from a single entity, being not a combination of processes, e.g. $\mathrm{Eu}^{2+}$ with $\mathrm{CT}$ or defects luminescence. The decay time at $77 \mathrm{~K}$ is around $1 \mu \mathrm{s}$, which is a typical value for $\mathrm{Eu}^{2+}$ luminescence. Therefore, it can be stated that the observed luminescence is originating from $\mathrm{Eu}^{2+}$ ions in the host.

The Figure 7 shows the comparison between the predicted and experimental emission curves, their similarity validating our theoretical prediction.

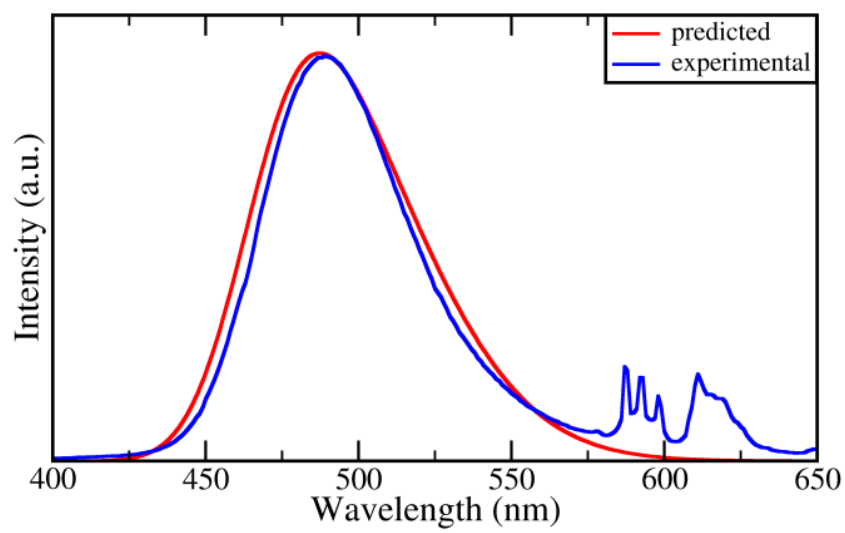

Figure 7. Comparison between the predicted and the experimental emission spectra of $\mathrm{BaSnSi}_{3} \mathrm{O}_{9}: \mathrm{Eu}^{2+}$ 
In summary, we have used computational methods to predict the luminescence properties of a new phosphor $\mathrm{BaSnSi}_{3} \mathrm{O}_{9}: \mathrm{Eu}^{2+}$, undertaking, a posteriori, the experimental check. The predicted emission wavelength $(488 \mathrm{~nm})$ is close to the experimentally retrieved value $(490 \mathrm{~nm})$. Besides, the predicted and measured FWHM and curve shapes are also extremely similar. The outlined methodology opens the door to the application of computational methods in the design of future lighting devices.

\section{Methods}

DFT calculations were performed with the VASP code. ${ }^{46,47}$ The PAW method was used to reproduce the interaction between the core electrons and the valence states. ${ }^{48,49}$ The exchange-correlation potential was written in the PBE approach. ${ }^{50}$ Simulations were performed in periodic supercells of 112 atoms, so interaction between $\mathrm{Eu}^{2+}$ images is negligible. The ground and excited configurations of $\mathrm{Eu}^{2+}$ were calculated by including the $4 \mathrm{f}$ electrons inside its core and fixing the number of $4 \mathrm{f}$ electrons to 7 and 6 , respectively. Starting structures for the calculations were obtaiden from available experimental data of the hosts. ${ }^{24,25,51}$

\section{Experimental Section}

The $\left(\mathrm{Ba}_{0.95} \mathrm{Eu}_{0.05}\right) \mathrm{SnSi}_{3} \mathrm{O}_{9}$ powder sample was synthesized via conventional solid state method. $\mathrm{BaCO}_{3}(99.8 \%$ Alfa Aesar), EuF (99.9\% Alfa Aesar), $\mathrm{SnO}_{2}$ (99.9\% Alfa Aesar) and nanoscale $\mathrm{SiO}_{2}$ $(99.5 \%$ Merck) were weighed in stoichiometric ratios and ground in an agate mortar employing $\mathrm{n}$-hexane as grinding medium. The powder was transferred to a corundum crucible and sintered in nitrogen $(99.999 \%$ Westfalen Gas) atmosphere at $1350{ }^{\circ} \mathrm{C}$ for 16 hours. Undoped $\mathrm{BaSnSi}_{3} \mathrm{O}_{9}$ was prepared by the same synthesis but without the addition of $\mathrm{EuF}_{2}$.

Excitation and emission spectra were recorded on an Edinburgh Instruments FLS920 spectrometer equipped with a Heraeus $450 \mathrm{~W}$ Xe arc lamp, mirror optics for powder samples and a cooled $\left(-20^{\circ} \mathrm{C}\right)$ singlephoton counting photomultiplier (Hamamatsu R2658P). The excitation spectra were corrected by use of a reference detector. The emission spectra were corrected with a correction file obtained from a tungsten incandescent lamp certified by the NPL (National Physics Laboratory, UK). Decay curves were recorded using the FLS 920 spectrometer equipped with a $375 \mathrm{~nm}$ laserdiode and a TCSPC card. Temperature dependent ,measurements were conducted using the same FLS920 spectrometer with an Oxford Instruments MicrostatN2 sample holder and liquid nitrogen as cooling agent.

XRD patterns were recorded on a Rigaku Miniflex II with $\mathrm{Cu} \mathrm{Ka} \mathrm{K}_{1,2}$ radiation.

\section{Acknowledgements}

FC notes the support of UEFISCDI grant PCE 108/2017. FB and TJ want to thank Merck KGaA, Germany for financial support.

Keywords: Density functional calculations $\cdot$ Ab initio calculations $\bullet$ Luminescence $\bullet$ Lanthanides

[1] S. Nakamura, G. Fasol, The Blue Laser Diode, Springer, 1997
[2] T. Jüstel, H. Nikol, C. Ronda, Angew. Chem. Int. Ed. 1998, 27, 2084.

[3] J.-C. Bünzli, C. Piguet, Chem. Soc. Rev. 2005, 34, 1048.

[4] H. A. Höppe, Angew. Chem. Int. Ed. 2009, 48, 3572

[5] X. Qin, X. Liu, W. Huang, M. Bettinelli, X. Liu, Chem. Rev. 2017, 117, 4488.

[6] C. W. E. van Eijk, Phys. Med. Biol. 2002, 47, R85.

[7] C. Ronda, Progress in Electromagtenic Research, 2014, 147, 81

[8] P. Pinho, K. Jokinen, L. Halonen, Lighting Res. Technol. 2012, 44, 427.

[9] H.-Q. Wang, M. Batenschuk, A. Osvet, L. Pinna, C. J. Bravee, Adv. Mater. 2011, 23, 2675

[10] N. Kunkel, P. Goldner, Z. Anorg. Allg. Chem. 2018, 644, 66.

[11] L. van Pieterson, M. F. Reid, G. W. Burdick, Phys. Rev. B 2002, 65 045114.

[12] P. S. Peijzel, P. Vergeer, A. Meijerink, M. F. Reid, L. A. Boatner, G. W Burdick, Phys. Rev. B 2005, 71, 045116.

[13] A. Canning, A. Chaudhry, R. Boutchki, N. Grønbech-Jensen, Phys. Rev. B 2011, 83, 125115 .

[14] M. Krośnicki, A. Kdziorski, L. Seijo, Z. Barandiarán, J. Phys. Chem. A 2014, 118, 358.

[15] H. Ramanantoanina, W. Urland, A. García-Fuente, F. Cimpoesu, C Daul, Chem. Phys. Lett. 2013 588, 260.

[16] H. Ramanantoanina, W. Urland, A. García-Fuente, F. Cimpoesu, C Daul, Phys. Chem. Chem. Phys. 2014, 16, 14625.

[17] C. Bulloni, A. García-Fuente, W. Urland, C. Daul, Phys. Chem. Chem. Phys. 2015, 17, 24925

[18] B. Herden, A. García-Fuente, H. Ramanantoanina, T. Jüstel, C. Daul, W. Urland, Chem. Phys. Lett. 2015, 620, 29.

[19] A. García-Fuente, A. Vega, Phys. Chem. Chem. Phys. 2017, 19, 15503

[20] G. Sánchez-Sanz, L. Seijo, Z. Barandiarán, J. Chem. Phys., 2010, 133 114509.

[21] M. de Jong, D. Biner, K. W. Krämer, Z. Barandiarán, L. Seijo, A. Meikerink, J. Phys. Chem. Lett., 2016, 7, 2730.

[22] M. De Jong, A. Meikerink, L. Seijo, Z. Barandiarán, J. Phys. Chem. C, 2017, 121, 10095

[23] D. Xu, W. Chen, M. Zeng, H. Xue, Y. Chen, X. Sang, Y, Xiao, T. Zhang R. R. Unocic, K. Xiao, L. Fu, Angew. Chem. Int. Ed. 2018, 57, 755.

[24] D.-Y. Wang, Y.-C. Wu, T.-M. Chen, J. Mater. Chem. 2011, 21, 18261.

[25] D.-Y. Wang, C.-H. Huang, Y.-C. Wu, T.-M. Chen, J. Mater. Chem. 2011 21, 10818.

[26] J. Y. Park, K. S. Shim, J. S. Yu, H. K. Yang, Mat. Lett. 2016, 173, 68

[27] Z. Barandiarán, L. Seijo, J. Chem. Phys., 2003, 119, 3785.

[28] R. Valiente, F. Rodríguez, J. González, H. U. Güdel, R. MartínRodríguez, L. Nataf, M. N. Sanz-Ortiz, K. Krämer, Chem. Phys. Lett., 2009, 481, 149

[29] S. Mahlik, K. Wisniewsky, M. Grinberg, R. S. Meltzer, J. Phys. Condens. Matter, 2009, 21, 245601.

[30] A. García-Fuente, F. Cimpoesu, H. Ramanantoanina, B. Herden, C Daul, M. Suta, C. Wickleder, W. Urland, Chem. Phys. Lett., 2015, 622, 120.

[31] R. D. Cowan, The Theory of Atomic Structure and Spectra, University of California Press, Ltd, Berkeley, 1981.

[32] M. V. Putz, F. Cimpoesu, M. Ferbinteanu, Structural Chemistry, Principles, Methods and Case Studies, Springer, 2018.

[33] B. Henderson, G. F. Imbusch, Optical spectroscopy of inorganic solids, Clarendon Press, Oxford, 1989.

[34] M. Gaft, L. Nagli, G. Waychunas, D. Weiss, Phys. Chem. Miner. 2004 $31,365$.

[35] E. B. Gross, J. E. N. Wainwright, B. W. Evans, Am Mineral. 1965, 50 1164

[36] K. Iwasaki, Y. Takahashi, H. Masai, T. Fujiwara, Opt. Express 2009, 17 18054.

[37] G. Blasse, A. Bril, J. Solid State Chem. 1970, 2, 105

[38] B. Moine, C. Pedrini, B. Courtois, J. Lumin., 1991, 50, 31.

[39] M. Raukas, S. A. Basun, W. van Schaik, W. M. Yen, U. Happek, Appl. Phys. Lett., 1996, 69, 3300.

[40] E. van der Kolk, J. T. M. De Haas, A. J. J. Bos, C. W. E. Van Eijk, P. Dorenbos, J. Appl. Phys., 2007, 101, 083703.

[41] H. Ni, H. Liang, Q. Su, Y. Tao, Y. Huang, Z. Gao, J. Am. Ceram. Soc. 2012, 95, 3197.

[42] C. Liu, Z. Xia, Z. Lian, J. Zhou, Q. Yan, J. Mater. Chem. C, 2013, 1 , 7139 
[43] J. Qin, H. Zhang, B. Lei, C. Hu, J. Li, Y. Liu, J. Meng, J. Wang, M. Zheng, Y. Xiao, J. Am. Ceram. Soc., 2013, 96, 3149.

[44] J. Chen, Y. Liu, L. Mei, H. Liu, M. Fang, Z. Huang, 2015, Sci. Rep. 5, 9673.

[45] D. Cui, Q. Xiang, Z. Song, Z. Xia, Q. Liu, J. Mater. Chem. C, 2016, 4, 7332.

[46] G. Kresse, J. Hafner, Phys. Rev. B 1993, 47, 558.

[47] G. Kresse, J. Furthmüller, Phys. Rev. B 1996, 54, 11169.

[48] P. Blöchl, Phys. Rev. B 1994, 50, 17953.

[49] G. Kresse, D. Joubert, Phys. Rev. B 1999, 59, 1758

[50] J. Perdew, K. Burke, M. Ernzerhof, Phys. Rev. Lett. 1996, 77, 3865

[51] J. Choisnet, A. Deschanvres, B. Raveau, J. Solid State Chem. 1972, 4, 209 


\section{Entry for the Table of Contents}

\section{COMMUNICATION}

Computational methods and quantum mechanics are used to predict the properties of a brand new phosphor based on $\mathrm{Eu}(\mathrm{II})$. Our prediction is confirmed by later experiments.

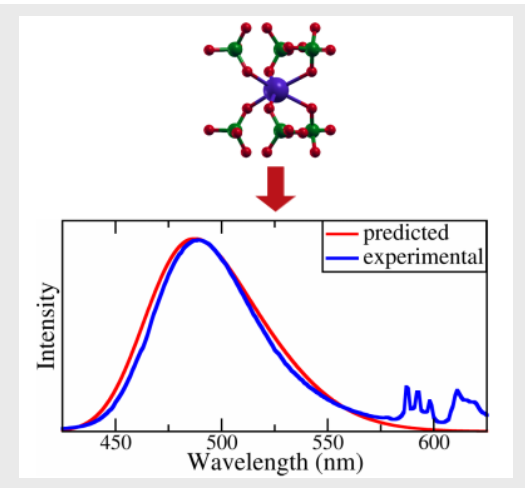

Author(s), Corresponding Author(s)*

Page No. - Page No.

Title 